\title{
Environmental Efficiency of Construction Industry with Considerations to Carbon Emission: A Case Study in Henan, China
}

\author{
Xin Youyang*(**)†, Li Xiuzhong*(**) and Shang li** \\ *Construction Engineering Quality Testing Research Center, Huanghuai University, Zhumadian 463000 China \\ **School of Civil Engineering, Huanghuai University, Zhumadian 463000, China \\ $†$ Corresponding author: Xin Youyang; 20070931@ @uanghuai.edu.cn
}

Nat. Env. \& Poll. Tech. Website: www.neptjournal.com

Received: 20-08-2021

Revised: 15-09-2021

Accepted: 22-09-2021

Key Words:

Carbon emissions

Construction industry

Environmental efficiency

Henan province

\section{ABSTRACT}

Low energy utilization is observed in China due to the extensive economic growth mode, which further leads to considerable energy wastes and environmental pollution. The construction industry plays an important role in the national economic development of China and consumes tremendous materials; thus, this industry discharges abundant $\mathrm{CO}_{2}$. The energy consumption growth rate of the construction industry in China is far higher than the national energy consumption growth rate, resulting in the prominent situation of high energy consumption and low yield. A case study based on Henan Province, China, was conducted to further analyze the environmental efficiency of the construction industry. An index system was established by using the Super-slack-based model (Super-SBM). This system chooses the following: labor, energy, capital, and technology of the construction industry as the input variables, economic output as the output variable, and carbon emissions as the unexpected output. This system was also used to investigate the energy efficiency of the construction industry in Henan Province from 2008 to 2019. Results demonstrated that the construction industry in Henan Province has failed to eliminate the extensive development mode thus far. The environmental efficiency of the construction industry presents a fluctuating growth with a mean of 1.048 , which generally remains at a relatively low level. The numbers of construction machines and enterprises in the construction industry have redundancy in approximately $50 \%$ of the years. Thus, this study can provide some positive references to enrich the evaluation index system and estimation model of energy efficiency of the construction industry, which includes unexpected output. Moreover, the current study can provide a comprehensive understanding of the environmental efficiency of the construction industry in a province in China and realize reasonable allocation of construction industrial resources.

\section{INTRODUCTION}

The continuous economic development provides people with pleasant lives, but such a life conceals considerable energy consumption and ecological environmental damages. The most prominent problem is global warming caused by excessive $\mathrm{CO}_{2}$ emissions. China continuously faces issues in high energy consumption and carbon emissions during economic development. Energy consumption is the primary source of carbon emission, and the construction industry has been one of the industries that consume the most energy in China. Urban scale continuously expands in China, which provides a demanding environment for the construction industry. Consequently, the energy consumption of the construction industry increases, thus generating a substantial amount of $\mathrm{CO}_{2}$. Except for the direct carbon emission from terminal energy consumption in the construction industry, construction products consume a substantial amount of building materials, such as steel and cement, which can generate abundant $\mathrm{CO}_{2}$. Assuring stable growth of construction industrial output is an important premise to reduce emissions of the industry. Such an assurance aims to maximize output and minimize $\mathrm{CO}_{2}$ emissions in the expected construction production activities. Therefore, increasing carbon emission efficiency shall be used as an important approach to decrease carbon emissions and promote the sustainable development of construction industries. The construction industry in China drives its development at the cost of abundant energy consumption, which prominently leads to high energy consumption and low output. Thus, increasing the energy efficiency of the construction industry in China is of considerable importance to save energy and improve the environment.

Henan Province is an area with an enormous population and large-scaled construction industrial development in central China. Fig. 1 shows that the national construction industry and the construction industry of Henan Province achieved rapid development from 2011 to 2020 . The total outputs of the national construction industry and the construction industry of Henan Province increased from 11,646.33 and 


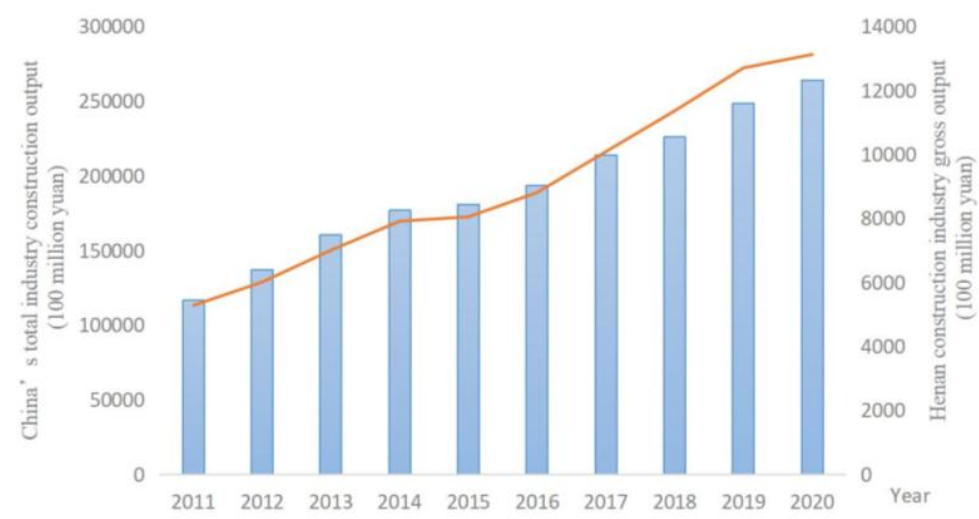

Fig. 1: Total outputs of the national construction industry and the construction industry of Henan Province from 2011 to 2020 (100 million yuan/RMB).

527.936 billion yuan (RMB) in 2011 to $26,394.704$ and 1312.255 billion yuan (RMB), showing an annual average growth rate of $14.07 \%$ and $16.50 \%$, respectively. Considering the total output of the construction industry, Henan Province is $2.43 \%$ higher than the national average level in China, which reflects the strong demands of Henan Province for construction industrial development. Carbon emissions of the construction industry in Henan Province continue to increase and cause serious pressure over ecological environments despite the rapid growth of the construction industry. This phenomenon is due to the generally low utilization of production resources, resource wastes, deficient management mechanisms in construction enterprises, and low construction technological levels. The current carbon emissions of the construction industry in Henan Province were estimated to discuss the carbon emission efficiency and facilitate energy-saving and emission reduction in the construction industry, which are beneficial to realizing the general emission reduction goal of China.

\section{PAST STUDIES}

In the background of continuous expansion of the construction industry, addressing the increasingly prominent construction industry-induced environmental pollution has attracted academic research attention worldwide. Numerous empirical studies have been conducted. Some scholars have reported successful studies on the environmental efficiency of construction industries and achieved some progress. Mandal et al. estimated the environmental efficiency of the cement industry in India. Empirical results revealed that the cement industry in India has sufficient potential to improve environmental efficiency, which varies among different states (Mandal et al. 2010). Feng et al. estimated two energy efficiencies and their decomposition indexes of the construction industry in China from 2004 to 2011. They also tested the influences of different external factors on the energy economic and environmental efficiencies of the construction industry of China. Their results demonstrated an increase in the regional average energy efficiency of the construction industry of China to some extent, and the low pure technological efficiency of construction energy is a major constraint against the energy efficiency of such an industry (Feng et al. 2015). Lin et al. discussed the relationship between $\mathrm{CO}_{2}$ emission reduction potentials and energy performances of the construction industry in China. They found that $\mathrm{CO}_{2}$ emission in the construction industry of China quickly increases, and electricity consumption has become a major emission source (Lin et al. 2015). Hu et al. discussed the environmental efficiency of the construction industry in Australia from 1990 to 2013 and found a significant increase during the study period. However, the gap among these industries increased due to seriously poor technological reforms (Hu et al. 2017). Wang et al. analyzed the social responsibility efficiency of the construction enterprises of China from 2012 to 2016. He found that these enterprises have not achieved optimal efficiency in fulfiling social responsibility. Institutional factors have complicated and nonlinear influences on the social responsibility efficiency of enterprises (Wang et al. 2018). Zhang et al. conducted an empirical study on the environmental efficiency of regional construction industries in China during 2006-2015 and found low carbon efficiency of building materials in most regions in the majority of provinces in China due to the low-efficiency material consumption (Zhang et al. 2018). Zhang et al. measured the technological efficiency of the regional construction industry in China by using a three-stage data envelopment analysis (DEA) model. They found that environmental monitoring had significant impacts on construction industrial efficiency in China, and scale efficiency demonstrated the most influence (Zhang et 
al. 2018). Xian et al. assessed the internal balance between environments for different types of energy consumption and costs in China's construction industry by using DEA technology. Results showed that the construction industry of China can produce the current level of industrial value-added at low $\mathrm{CO}_{2}$ emissions and energy input cost by eliminating technologies with low efficiency and adjusting energy consumption structure (Xian et al. 2019). Zhou et al. estimated the total factor carbon emission efficiency of the construction industry in China from 2003 to 2016 by using the super SBM-DEA method. Empirical results revealed that the carbon emission efficiency of China's construction industry is relatively low and presents a decreasing trend. Technological progress and energy restructuring can promote carbon emission efficiency of the construction industry, but the economic scale of the extensive development model may generate some negative impacts (Zhou et al. 2019). Du et al. established a static computable general equilibrium model to discuss the rebounding effect of different energy sources used in the construction industry. Results showed that coal, petroleum, natural gas, and electricity are major energy sources of the construction industry in China, and increasing the energy efficiency of the construction industry had positive effects on relieving GDP and carbon emission (Du et al. 2019). Le et al. studied 600 building material enterprises in Vietnam through a questionnaire and found that environmental efficiency also had strong positive effects on financial efficiency. Therefore, innovative solutions of decreasing environmental pollution can increase the profitability of enterprises (Le et al. 2019). Zhang et al. measured the environmental efficiency of the construction industry in China from 2000 to 2017 and analyzed the degree of influencing factors through Tobit regression. Their results indicated a significant disconnection between the R\&D stage and commercial application stage of green technology in the construction industry in China (Zhang et al. 2021). Liang et al. measured energy efficiencies of construction industries in 30 provinces in China from 2008 to 2017 by using a threestage DEA-Malmquist model. They found that total factor energy efficiency changes (TFEECH) and technological changes (TECH) of China's construction industry had been underestimated. Per capita glass steel, energy consumption structure, industrial development degree, and industrial concentration degree all had positive effects on energy efficiency improvement (Liang et al. 2021). Chen et al. estimated the energy efficiency of China's construction industry from 2005 to 2016 by using an SBM-DEA model. The empirical results revealed that the low management efficiency of the construction industry is an important cause of the low energy efficiency of the construction industry in China (Chen et al. 2021). The literature review on the environmental efficiency of construction industries found that foreign scholars mainly focused on the micro-enterprise layer, while Chinese scholars conducted measurement and comparative analysis of the local region or national layer. Moreover, most research results show that the construction industry has caused heavy energy consumption and environmental pollution due to its high energy consumption. However, the environmental efficiency of the construction industry has been improving yearly due to the applications of new technologies and high-intensity environmental regulations and policies in different countries. Therefore, a case study based on Henan Province, China, was conducted in accordance with the above studies. Research conclusions are conducive to further comprehend the estimation methods of environmental efficiency of the construction industry and general construction industry development in Henan Province within the corresponding calculation stages.

\section{MODELS AND DATA SPECIFICATION}

\section{Models}

As an extended model of DEA, SBM has many advantages: setting production function and zero influences of index dimensions in solving efficiency is no longer necessary, considerations to multiple input and output indexes, and objective empowerment. Among these advantages, the unexpected output SBM model offsets the disadvantages of the radial DEA model, including invalid measurement and exclusion of slack variables. Thus, the unexpected output SBM model can analyze specific causes of invalid outputs by reducing (or increasing) the percentage of corresponding slack variables. Therefore, the decision-making units (DMUs) on the data envelope leading edge in the same investigation period (efficiency value is 1) were compared by super-efficiency, thus realizing an accurate measurement of comprehensive DMU efficiency. The model is described as follows. Suppose $n$ DMUs are available. The years of Henan Province were used as DMUs in this study. Each DMU contains $m$ inputs, $s$ expected outputs, and $k$ unexpected outputs. The input elements include labor, capital, and energy of the construction industry when the research object is the energy efficiency of the construction industry. Meanwhile, the expected outputs are the construction industrial output, and the unexpected outputs are chosen as the carbon emission caused by construction industrial development. Consequently, the input matrix of the construction industry is shown in Eq. (1), and the expected output matrix is Eq. (2). The unexpected output matrix is presented in Eq. (3).

$$
\begin{aligned}
& X=\left(x_{1}, x_{2}, \cdots x_{m}\right) \in R_{m \times n}, \\
& Y=\left(y_{1}, y_{2}, \cdots y_{s}\right) \in R_{s \times n}, \\
& U=\left(u_{1}, u_{2}, \cdots u_{k}\right) \in R_{k \times n} .
\end{aligned}
$$


According to Eqs. (1)-(3) and the study of Tone, K., the production possibility set can be obtained as follows (Tone, K., 2001):

$$
P=\{(x, y, u) \mid x \geq \lambda X, y \geq \lambda Y, u \geq \lambda U, \lambda \geq 0\} .
$$

The SBM model of the unexpected output is:

$$
\begin{aligned}
& \rho_{0}^{*}=\min \frac{1-\frac{1}{m} \sum_{i=1}^{m} \frac{S_{i o}^{-}}{x_{i o}}}{1+\frac{1}{s+k}\left(\sum_{r=1}^{s} \frac{S_{r o}^{g}}{y_{r o}}+\sum_{q=1}^{k} \frac{S_{q o}^{b}}{u_{q o}}\right),} \\
& \text { s.t. }\left\{\begin{array}{l}
x_{i o}=\sum_{j=1}^{n} \lambda_{j} x_{i j}+S_{i o}^{-}, i=1,2, \ldots, m ; \\
y_{r o}=\sum_{j=1}^{n} \lambda_{j} x_{r j}-S_{r o}^{g}, r=1,2, \ldots, s ; \\
u_{r o}=\sum_{j=1}^{n} \lambda_{j} x_{q j}+S_{q o}^{b}, q=1,2, \ldots, k ;
\end{array}\right. \\
& \lambda_{j} \geq 0, j=1,2, \ldots n ; S_{i o}^{-}, S_{r o}^{g}, S_{q o}^{b} \geq 0
\end{aligned}
$$

where $x_{i o}, y_{r o}, u_{q o}, \lambda$ are the input $i$ of year $o$, expected output $r$, unexpected output $q$, and linear combination coef-

ficient of year $j$, respectively. $S_{i o}^{-}, S_{r o}^{-}, S_{q o}^{-}$are slack variables of the input $i$, expected output $r$, and unexpected output $q$ in the year of $o$, respectively. $\rho_{0}^{*}$ is the efficiency value in the year of $o . \mathrm{DMU}_{\mathrm{k}}$ is SBM effective only when $\rho_{0}^{*}=1$ or $S_{i o}^{-}=0, S_{r o}^{-}=0, S_{q o}^{-}=0$, and the energy efficiency of the construction industry in the year of $k$ is relatively ideal.

\section{Data Specification}

Considering research status, labor, energy, capital, and technology of the construction industry in Henan Province were chosen as input variables according to the research objective of this study and data availability. Specifically, the following input variables are included: (1) labor input, which is expressed by the number of construction enterprises in Henan Province; (2) capital input, which is expressed by the paid-in capitals of construction enterprises in Henan Province; (3) energy input, which is expressed by the energy input of the construction industry in Henan Province; (4) technological input, which is expressed by the number of construction machines in construction enterprises. The output is expressed by the total construction industrial output. Unexpected output is the carbon emission of the construction industry in Henan Province. The research object used the construction industry in Henan Province considering data availability and consistency, and the study period was determined from 2008 to 2019. All original data came from the Statistical Yearbook of Henan Province, China, Energy Statistical Yearbook, and Statistical Yearbook of China's Construction Industry from 2009 to 2020. The carbon emissions of the construction industry were calculated in accordance with the previous Regional Energy Sheet of Henan Province. Descriptive statistical results of specific indexes and data are listed in Table 1.

\section{EMPIRICAL STUDY}

The calculation of the super-efficiency SBM model considering improved slack variables, including unexpected output, used DEA-SOLVER Pro5.0 in this study. This model evaluated the energy efficiency of the construction industry in Henan Province from 2008 to 2019.

Table 2 shows that most input and output indexes generally have low levels of redundancy and energy efficiency of the construction industry in Henan Province. Thus, the input and output can still be substantially improved.

Fig. 2 shows that the energy efficiency of the construction industry in Henan Province from 2008 to 2019 generally

\begin{tabular}{|c|c|c|c|c|c|c|}
\hline $\begin{array}{l}\text { Index } \\
\text { type }\end{array}$ & Input indexes & & & & Output indexes & $\begin{array}{l}\text { Unexpected output } \\
\text { indexes }\end{array}$ \\
\hline $\begin{array}{l}\text { Specific } \\
\text { index }\end{array}$ & $\begin{array}{l}\text { Energy input } \\
\text { of construction } \\
\text { industry } \\
\text { ( } 10,000 \text { tons of } \\
\text { standard coals) }\end{array}$ & $\begin{array}{l}\text { Number of construc- } \\
\text { tion machines in con- } \\
\text { struction enterprises } \\
\text { (pc) }\end{array}$ & $\begin{array}{l}\text { Paid-in capitals } \\
\text { of construction } \\
\text { enterprises } \\
\text { ( } 100 \text { million } \\
\text { yuan) }\end{array}$ & $\begin{array}{l}\text { Number of } \\
\text { construction } \\
\text { enterprise } \\
\text { (pc) }\end{array}$ & $\begin{array}{l}\text { Total output of con- } \\
\text { struction industry } \\
\text { ( } 100 \text { million yuan) }\end{array}$ & $\begin{array}{l}\text { Carbon emissions of } \\
\text { construction industry } \\
\text { (100 million tons) }\end{array}$ \\
\hline $\operatorname{Max}$ & 102.00 & $61,4338.00$ & 453.75 & 3827.00 & 2824.05 & 74.00 \\
\hline Min & 569.00 & $81,8851.00$ & 2143.18 & 6740.00 & $12,701.68$ & 297.00 \\
\hline SD & 176.06 & $60,788.09$ & 611.37 & 891.24 & 3083.93 & 90.08 \\
\hline Mean & 272.33 & $691,468.50$ & 1253.27 & 4898.08 & 7335.76 & 155.95 \\
\hline Median & 172.34 & $678,129.00$ & 1168.73 & 4690.50 & 7457.55 & 124.05 \\
\hline
\end{tabular}
increased slowly in a fluctuating manner. Specifically, the energy efficiency of the construction industry continuously

Table 1: Statistical system index and descriptive statistical results. 
increased during 2008-2014, with an annual growth rate of $9 \%$. Subsequently, the energy efficiency generally decreased continuously, achieving an annual fluctuating growth rate of $1.3 \%$ from 2017 to 2019. The mean energy efficiency of the construction industry in Henan Province was 1.048 from 2008 to 2019. This value indicated that the construction industry of Henan Province has achieved some success in transition development mode and energy output improvement. Nevertheless, the energy efficiency was generally low, showing an invalid state. This finding revealed that the construction industry of Henan Province is still subordinated to the extensive development mode and has not achieved the coordinated development between output growth and resource environmental protection. Thus, this industry has a long way to go in development transformation, resource-saving, and environmental protection. For input variables, the number of machines of construction enterprises (pc) and that of construction enterprises $(\mathrm{pc})$ have redundancy in approximately $50 \%$ of years. This result proves that technological input to the construction industry of Henan Province has not been maximized, and numerous construction machines have no functions of improving energy efficiency completely. Thus, future work shall provide additional attention to the internal management of construction enterprises and use advanced environmental protection technology to decrease emissions of wastes. Many construction enterprises are available, but

Table 2: Slack Statistical Sheet and Means of Super-Efficiency SBM.

\begin{tabular}{|c|c|c|c|c|c|c|c|c|}
\hline \multirow[t]{3}{*}{ No. } & \multirow[t]{3}{*}{ DMU } & \multirow[t]{3}{*}{ Score } & Excess & Excess & Excess & Excess & Shortage & Shortage \\
\hline & & & 1 & 2 & 3 & 4 & 1 & (OBad) \\
\hline & & & S-(1) & S-(2) & S-(3) & S-(4) & $S+(1)$ & $S+(2)$ \\
\hline 1 & 1 & 1.145590631 & 11.99886 & $65,673.19982$ & 132.1341411 & 254.95918 & 0 & 0 \\
\hline 2 & 2 & 0.949541904 & 2.545966266 & $38,876.84672$ & 0 & 121.6225195 & 0 & 3.849330393 \\
\hline 3 & 3 & 1.004044659 & 0 & $10,521.19357$ & 0 & 0 & 0 & 0 \\
\hline 4 & 4 & 1.001225432 & 0 & 0 & 3.781438146 & 0 & 0 & 0 \\
\hline 5 & 5 & 1.027440934 & 0 & 2022.017136 & 0 & 64.08442227 & 269.5789778 & 0 \\
\hline 6 & 6 & 1.02832062 & 0 & 0 & 17.13265448 & 0 & 326.5036423 & 0 \\
\hline 7 & 7 & 1.219920843 & 108.2846129 & 0 & 0 & 60.56679006 & 508.8824136 & 0 \\
\hline 8 & 8 & 1.032799689 & 0 & 7625.853782 & 0 & 559.3657142 & 0 & 0 \\
\hline 9 & 9 & 1.005185355 & 0 & $13,387.75804$ & 0 & 0 & 0 & 0 \\
\hline 10 & 10 & 1.073532043 & 0 & 657.033142 & 0 & 0 & 0 & 40.13756065 \\
\hline 11 & 11 & 1.002037367 & 0 & 0 & 0 & 50.19256551 & 0 & 0 \\
\hline 12 & 12 & 1.087633456 & 0 & 18849 & 0 & 0 & 1341.16 & 12.585348 \\
\hline
\end{tabular}

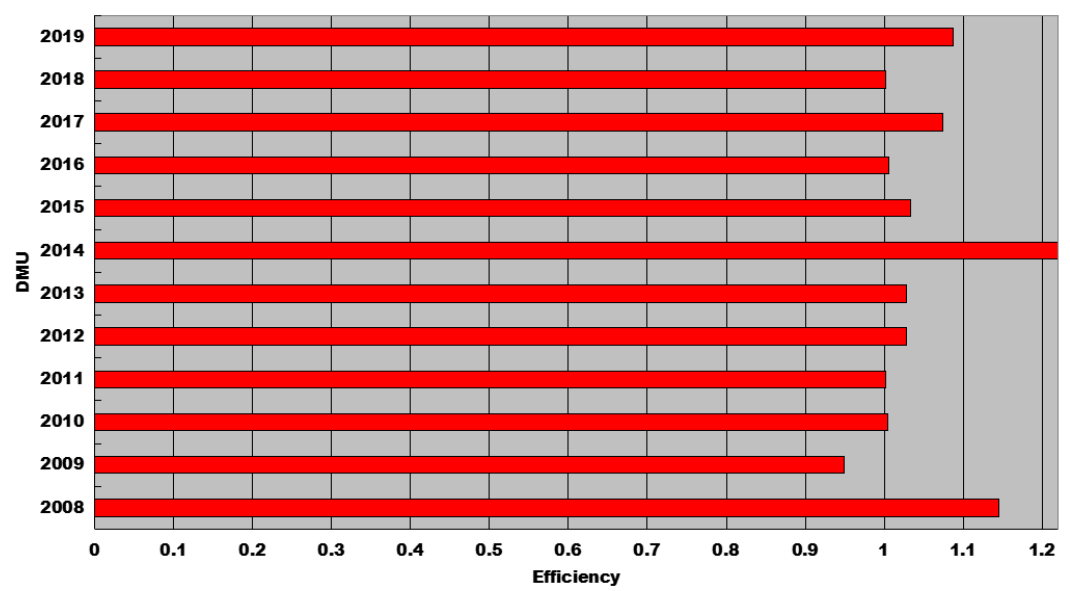

Fig. 2: Mean of annual energy efficiency of the construction industry from 2008-2019. 
the general construction industrial level in Henan Province is relatively low. The raw material input increases with the expansion of enterprise production scale, and the resource waste phenomenon emerges, accompanied by rising waste emissions. Therefore, the quantity scale of the construction industry shall be appropriately controlled, and construction industry development shall be strengthened to realize the large-scale economic benefits of construction industries in Henan Province.

\section{POLICY SUGGESTIONS}

\section{Strengthen Scientific Input and Control the Scale of Construction Industry Appropriately}

The construction industry is a complicated huge system, and many influencing factors affect environmental efficiency. The input scale of the construction industry is recently expanding gradually, and the factor inputs of capital and labor are continuously increasing with the rapid development of the construction industry. Increasing the labor input in a long period may not always promote output growth due to influences by the decreasing laws of marginal benefits. Recent studies indicate that labor input has a small contribution to output growth, and such contributions gradually decrease. Conclusions of most studies disclose to some extent that abundant factor inputs to construction industries have not been properly managed and developed, thus influencing the output growth. This finding implies that simple scale expansion of the construction industry may not always increase environmental efficiency. Hence, the key to improving the environmental efficiency of the construction industry is to change the input-driven extensive economic growth mode rather than expand the industrial scale. Promoting reasonable allocation of resources, comprehending resource demands, comprehensively using construction projects by employing informatization and modernized means, and decreasing resource wastes are suggested. These suggestions facilitate production efficiency improvement of the construction industry.

\section{Adjust Energy Consumption Structure of Construction Industry and Increase its Market Openness}

A considerable amount of support shall be given to $R \& D$ and the usage of environmental-friendly energy sources. The construction industry heavily relies on traditional energy sources. Carbon emission coefficients of energy sources, such as crude coals and coke, are relatively high and have substantial contributions to direct carbon emissions of the construction industry. Carbon emission coefficients of environmental-friendly energy sources, such as electricity, are relatively low, and these energy sources are renewable.
Hence, these coefficients can adjust prices of environmental-friendly energy sources (e.g., electricity and natural gas) or increase subsidies to the use of environmental-friendly energy sources to encourage the replacement of traditional high-carbon energy sources. Meanwhile, building a platform for communication between universities and enterprises, promoting $\mathrm{R} \& \mathrm{D}$ of environmental-friendly energy sources positively, and decreasing carbon emission caused by traditional energy consumption are also suggested. Such suggestions increase the carbon emission efficiency of the construction industry. Moreover, subsidies to state-owned construction enterprises for innovation shall be increased to promote their enthusiasm for emission reduction. The rich resources and development stability introduced by state-owned systems of construction enterprises decrease the production enthusiasm of workers and reduce technological innovation efficiency. These conditions are disadvantageous to the improvement of the carbon emission efficiency of construction industries. Therefore, the market openness of the construction industry shall be increased and effective market competition shall be formed to promote the technological progress of construction enterprises.

\section{Optimize the Design of Construction Products and Decrease Consumption of Building Materials}

The development and use of new environmental-friendly materials shall be encouraged. At present, building materials mainly include steel, cement, glass, and aluminum. Among these materials, only steel and aluminum can be recycled. However, carbon emissions of the five building materials are significantly higher than that of energy consumption. These materials are also major contributors to carbon emissions in the construction industry. Therefore, decreasing the use of traditional building materials is suggested to reduce carbon emissions and thereby promote the improvement of efficiency. On the one hand, the design of construction products shall be optimized to decrease the usage of building materials from the design end while assuring the product performance, finally reducing carbon emissions. On the other hand, R\&D of new environmental-friendly materials shall be increased to replace the traditional building materials. Meanwhile, recommendations include reducing the market price of the new materials by combining the market mechanism and providing subsidies to enterprises for using new materials to promote their applications.

\section{Increase Support to Low-Carbon Development of Construction Industry and Strengthen Regional Cooperation}

The government shall increase support to the low-carbon 
development of the construction industry in economically underdeveloped regions to promote green development of the construction industry, publicize the energy-saving and environmental-protection concept positively, increase subsidies for construction technological innovation, and promote the improvement of production efficiency. Moreover, building a platform for low-carbon construction communication and encouraging provinces with high carbon emissions of the construction industry to learn the construction energy-saving technology from advanced provinces are suggested. Regional cooperation shall be strengthened to promote common development among different provinces in energy saving and emission reduction of the construction industry. Therefore, the government shall strengthen inter-provincial communication and learning, develop the driving role of high-efficiency regions, set up trans-provincial emission reduction plans of the construction industry, break traditional administrative zoning barriers, guide the transfer of low-carbon philosophy and low-carbon technology in high-efficiency regions to low-efficiency regions, and promote coordinated development among regions.

\section{CONCLUSIONS}

As a resource-intensive industry, the construction industry absorbs abundant resources, except for human and social resources, during its continuous expansion. This phenomenon causes massive energy consumptions and discharges tremendous $\mathrm{CO}_{2}$ due to low construction levels, mechanization, and accomplishment of workers in China's construction industry. Consequently, such an absorption causes considerable pressure on the ecological environment. A case study based on Henan Province, China, is conducted in this study. An index system is established by using the Super-SBM model to discuss the energy efficiency of the construction industry in Henan Province from 2008 to 2019. This index system chooses labor, energy, capital, and technology as input variables, economic output as output variable, and carbon emission as the unexpected output. The results demonstrate that the construction industry in Henan Province has failed to eliminate the extensive development mode thus far. The environmental efficiency of the construction industry generally presents a relatively low fluctuating growth with a mean of 1.048. In the construction industry, the numbers of construction machines and enterprises demonstrate redundancy in approximately $50 \%$ of the years. Finally, some policy suggestions, including strengthening scientific input to the construction industry, adjusting its energy consumption structure, optimizing the design of building products, and increasing support to the low-carbon development of the industry, are proposed. Future works shall investigate the influencing factors of China's construction industrial development and provincial differences in carbon emission efficiency of the construction industry by prolonging time frames of data related to the construction industry and choosing appropriate indexes.

\section{ACKNOWLEDGMENT}

This work was supported by the Science and Technology Planning Development Project in Henan Province (192102310516); and the Key Scientific Research Project of the Colleges and Universities in Henan Province( 21B560007, 22B560009).

\section{REFERENCES}

Chen, Y., Ma, L. and Zhu, Z. 2021. The environmental-adjusted energy efficiency of China's construction industry: a three-stage undesirable SBM-DEA model. Environmental Science and Pollution Research, $1-14$.

Du, Q., Li, Z., Li, Y., Bai, L., Li, J. and Han, X. 2019. Rebound effect of energy efficiency in China's construction industry: a general equilibrium analysis. Environmental Science and Pollution Research, 26(12): 12217-12226

Feng, B. and Wang, X. Q. 2015. Empirical research on energy economic efficiency and energy environmental efficiency of China's construction industry: based on the SBM-tobit two-stage model. Journal of Beijing Institute of Technology (Social Sciences Edition), 17(1): 14-22.

$\mathrm{Hu}, \mathrm{X}$. and Liu, C. 2017. Slacks-based data envelopment analysis for eco-efficiency assessment in the Australian construction industry. Construction Management and Economics, 35(11-12): 693-706.

Lin, B. and Liu, H. 2015. $\mathrm{CO}_{2}$ mitigation potential in China's building construction industry: A comparison of energy performance. Building and Environment, 94: 239-251.

Liang, X., Lin, S., Bi, X., Lu, E. and Li, Z. 2021. Chinese construction industry energy efficiency analysis with undesirable carbon emissions and construction waste outputs. Environmental Science and Pollution Research, 28(13): 15838-15852.

Le, T. T., Nguyen, T. M. A. and Phan, T. T. H. 2019. Environmental management accounting and performance efficiency in the Vietnamese construction material industry-A managerial implication for sustainable development. Sustainability, 11(19): 5152.

Mandal, S. K. and Madheswaran, S. 2010. Environmental efficiency of the Indian cement industry: an interstate analysis. Energy Policy, 38(2): 1108-1118

Tone, K. 2001. A slacks-based measure of efficiency in data envelopment analysis. European Journal of Operational Research, 130(3): 498-509.

Wang, X., Lai, W., Song, X. and Lu, C. 2018. Implementation efficiency of corporate social responsibility in the construction industry: A China study. International Journal of Environmental Research and Public Health, 15(9): 2008.

Xian, Y., Yang, K., Wang, K., Wei, Y. M. and Huang, Z. 2019. Cost-environment efficiency analysis of construction industry in China: A materials balance approach. Journal of Cleaner Production, 221: 457-468.

Zhou, Y., Liu, W., Lv, X., Chen, X. and Shen, M. 2019. Investigating interior driving factors and cross-industrial linkages of carbon emission efficiency in China's construction industry: Based on Super-SBM DEA and GVAR model. Journal of Cleaner Production, 241: 118322.

Zhang, J., Li, H., Xia, B. and Skitmore, M. 2018. Impact of environment regulation on the efficiency of regional construction industry: a 3-stage Data Envelopment Analysis (DEA). Journal of Cleaner Production, 200: 770-780. 
Zhang, J., Ouyang, Y., Ballesteros-Pérez, P., Li, H., Philbin, S. P., Li, Z. and Skitmore, M. 2021. Understanding the impact of environmental regulations on green technology innovation efficiency in the construction industry. Sustainable Cities and Society, 65: 102647.
Zhang, P., You, J., Jia, G., Chen, J. and Yu, A. 2018. Estimation of carbon efficiency decomposition in materials and potential material savings for China's construction industry. Resources Policy, 59: 148-159. 